\title{
The Medial Prefrontal Cortex is Both Necessary and Sufficient for the Acquisition of Conditioned Defeat
}

\author{
Chris M. Markham, Cloe A. Luckett, and Kim L. Huhman \\ The Neuroscience Institute, Georgia State University, Atlanta, GA USA, 161 Jesse Hill Jr. Drive, \\ Suite 832, Atlanta, GA 30303
}

\begin{abstract}
We have previously demonstrated that the basolateral amygdala (BLA) is a key component of a neural circuit mediating memory formation for emotionally relevant stimuli in an ethologicallybased model of conditioned fear, termed conditioned defeat (CD). In this model, subjects are socially defeated by a larger, more aggressive hamster. Upon subsequent exposure to a smaller, non-aggressive intruder, the defeated animal will show high levels of submissive behaviors and fail to defend its territory. Here we examined whether the medial prefrontal cortex (mPFC), an area with extensive connections with the amygdala, is also a component of this circuit. Temporary inactivation of the $\mathrm{mPFC}$ using muscimol, a $\mathrm{GABA}_{\mathrm{A}}$ receptor agonist, significantly enhanced the acquisition but not expression of $\mathrm{CD}$, while blockade of $\mathrm{GABA}_{\mathrm{A}}$ receptors in the $\mathrm{mPFC}$ using bicuculline, a $\mathrm{GABA}_{\mathrm{A}}$ antagonist, impaired acquisition of $\mathrm{CD}$. Given these findings, we next sought to test whether plasticity related to the defeat experience occurs in the mPFC. We infused anisomycin, a protein synthesis inhibitor, in the mPFC but this treatment did not alter the acquisition of $\mathrm{CD}$. In our final experiment, we demonstrated that bicuculline failed to alter the acquisition of $\mathrm{CD}$. Together, these results demonstrate for the first time that while the $\mathrm{mPFC}$ is both necessary and sufficient for the acquisition of $\mathrm{CD}$, it does not appear to mediate plasticity related to the defeat experience. In contrast, while plasticity underlying CD does appear to occur in the BLA, GABAergic receptor inhibition in the BLA is not sufficient to enhance CD.
\end{abstract}

\section{Keywords}

social stress; amygdala; defensive behavior; conditioned fear; aggression

\section{Introduction}

Our lab has identified the primary components of an integrated neural circuit underlying conditioned defeat (CD), a learned response whereby socially defeated Syrian hamsters (Mesocricetus auratus) display submissive and defensive behaviors instead of territorial aggression when they are subsequently paired with a non-aggressive conspecific (Huhman et al., 2003; Potegal et al., 1993). We have also gathered substantial evidence that the amygdala, in particular the basolateral complex (BLA), is a critical component of this circuit because temporary inactivation of the BLA (via muscimol infusion) impairs the acquisition

\footnotetext{
(C) 2011 Elsevier Ltd. All rights reserved.

Corresponding Author: Chris M. Markham, Ph.D., cmarkham1@gsu.edu, Tel: 1.404.413.6337, Fax: 1.404.413.5471, The Neuroscience Institute, Georgia State University, 161 Jesse Hill Jr. Drive, Suite 832, Atlanta, GA 30303, USA.

Publisher's Disclaimer: This is a PDF file of an unedited manuscript that has been accepted for publication. As a service to our customers we are providing this early version of the manuscript. The manuscript will undergo copyediting, typesetting, and review of the resulting proof before it is published in its final citable form. Please note that during the production process errors may be discovered which could affect the content, and all legal disclaimers that apply to the journal pertain.
} 
and expression of CD (Jasnow and Huhman 2001; Markham et al., 2010). Importantly, plasticity related to the defeat experience also appears to be mediated in the BLA because overexpression of cAMP response element-binding protein (CREB) enhances the acquisition of $\mathrm{CD}$ whereas pre-training infusion of anisomycin, a protein synthesis inhibitor, or ifenprodil, a NMDA receptor (NR2B subunit) antagonist, both block the acquisition of CD (Day et al., 2011; Jasnow et al., 2005; Markham and Huhman, 2008). These findings are consistent with a large number of studies showing that the amygdala is necessary for the acquisition and expression of conditioned fear in more traditional models such as auditory fear conditioning and fear-potentiated startle (Davis, 1997, 2000; LeDoux, 2000; Maren, 2001; Walker and Davis, 2002).

The prelimbic/infralimbic cortex (corresponding to the medial prefrontal cortex (mPFC)) is an area that has extensive connections with the amygdala (McDonald et al., 1996), and it is a site which we have yet to investigate for its possible role in $\mathrm{CD}$. Like the amygdala, the $\mathrm{mPFC}$ has also been implicated in fear learning, including acquisition (Morgan and LeDoux, 1995; Morgan et al., 1993), expression (Sierra-Mercado et al., 2006) and extinction (Milad and Quirk, 2002; Morgan et al., 1993; Quirk et al., 2003) of conditioned fear. In addition, several lines of evidence suggest a functional interaction between the two areas whereby the $\mathrm{mPFC}$ acts to inhibit the activity of the amygdala via glutamatergic projections (Smith et al., 2000) to GABAergic intercalated (IC) cells, which in turn induce feedforward inhibition of the output neurons in the amygdala (Quirk et al., 2003). While Quirk and colleagues (2003) acknowledge that it is possible that other structures receiving direct projections from the mPFC (such as the periaqueductal gray (Floyd et al., 2000) and hypothalamus (Floyd et al., 2001) are responsible for the inhibition of fear responses to conditioned stimuli independent of the amygdala, this does not seem to be the case because direct stimulation of the mPFC reduces the responsiveness of amygdalar output neurons in a site-specific manner (Milad et al., 2004; Quirk et al., 2003).

The primary aim of the present series of experiments was to determine whether the $\mathrm{mPFC}$ is part of the neural circuit mediating CD. If the mPFC exerts a feedforward inhibition of the amygdala, then temporary inactivation of the $\mathrm{mPFC}$ should enhance, while temporary activation should impair the acquisition of CD. We also asked whether protein synthesis in the $\mathrm{mPFC}$ is necessary for the formation of CD. Finally, we also sought to determine whether blockade of GABAergic receptors in the BLA would be sufficient to enhance the acquisition of conditioned defeat.

\section{Methods and Procedures}

\subsection{Animals and housing conditions}

Subjects in all experiments were adult male Syrian hamsters (Mesocricetus auratus, Charles River Laboratories, New York, NY) that weighed 120-140 g and were between 9-10 weeks old at the time of testing. Upon arrival, they were housed in groups of 5-6 per cage for one week (as a quarantine measure) prior to the start of any manipulation. Animals were housed in a temperature $\left(20 \pm 2^{\circ} \mathrm{C}\right)$ and humidity-controlled room with free access to food and water and were kept on a 14:10 h light: dark cycle with lights out at $1100 \mathrm{~h}$. All training and testing sessions were performed under dim red light illumination during the first 3 hours of the dark phase of the light-dark cycle in order to minimize circadian effects. Resident aggressors (RA) used for defeat training were older (> 6 months), singly housed males weighing between 170 and $195 \mathrm{~g}$, while younger males ( 2 months), weighing between 110 and $120 \mathrm{~g}$, were group housed (5-6 per cage) and served as non-aggressive intruders (NAI). All procedures and protocols were approved by the Georgia State University Institutional Animal Care and Use Committee and are in accordance with the standards outlined in the National Institutes of Health Guide for Care and Use of Laboratory Animals. 


\subsection{Surgical Procedures}

One week after arrival, subjects were anesthetized with sodium pentobarbital $(90 \mathrm{mg} / \mathrm{kg}$, i.p., Lundbeck, Inc., Deerfield, IL) and were placed into a stereotaxic frame (David Kopf Instruments, Tujunga, CA). For the medial prefrontal cortex, a stainless steel guide cannula (26-gauge, Plastics One, Roanoke, VA), held at a $20^{\circ}$ angle toward the midline, was unilaterally implanted in either the left or right hemisphere $(3.2 \mathrm{~mm}$ rostral and $\pm 1.6 \mathrm{~mm}$ lateral relative to bregma and $3.2 \mathrm{~mm}$ below dura). In order to minimize tissue damage to the area of interest, a smaller, 33-gauge injection needle (Plastics One, Roanoke, VA) that projected $1.2 \mathrm{~mm}$ below the guide cannula was used on injection day in order to reach a final depth of $4.4 \mathrm{~mm}$ below dura. For the basolateral amygdala, stainless steel guide cannula identical to the ones used above were bilaterally implanted in the following coordinates: $0.2 \mathrm{~mm}$ rostral and $\pm 3.4 \mathrm{~mm}$ lateral relative to bregma and $2.1 \mathrm{~mm}$ below dura. Again, in order to minimize tissue damage, a 33-gauge injection needle that projected 4.2 $\mathrm{mm}$ below the guide cannula and reaching a final depth of $6.3 \mathrm{~mm}$ below dura was used for the injection procedure. Following surgery, dummy stylets were placed in the guide cannula to help maintain patency and $1 \mathrm{cc}$ of warm physiological saline and $0.1 \mathrm{cc}$ of ketoprofen (Fort Dodge Animal Health, Fort Dodge, IA) was injected subcutaneously in order to aid in recovery. Hamsters were allowed 7-10 days to recover prior to the start of behavioral testing during which they were monitored daily to ensure that there was no adverse outcome from the surgery. Three days prior to the start of the experiment, subjects were handled by gently restraining them and removing and replacing the dummy stylet in order to maintain patency and to habituate the subjects to the infusion procedure.

\subsection{Social defeat and behavioral testing}

On the day of social defeat training, animals were transported to our testing suite within the vivarium and allowed to acclimate for at least $30 \mathrm{~min}$. Training sessions consisted of a single 15 min (full defeat) or 5 min (sub-optimal defeat) exposure to the RA in the aggressor's home cage, upon which the RA reliably attacked the experimental hamster within $60 \mathrm{~s}$. During the training session, attacks by the RA against the subject occur only sporadically in bouts, and do not last for the entire duration of the session. All training and testing sessions were recorded via a CCD camera positioned overhead. Twenty-four hours after defeat, subjects were transported to the testing suite and allowed to acclimate for at least $30 \mathrm{~min}$, after which a NAI was introduced into each subjects' home cage for $5 \mathrm{~min}$. The trials were recorded and scored by an observer that was blind to the experimental conditions using the behavioral analysis software Hindsight (developed by Scott Weiss, $\mathrm{Ph} . \mathrm{D}$.). The total duration of four classes of behaviors were scored during the testing session: (a) social behavior (stretch, approach, sniff, nose touching and flank marking), (b) non-social behavior (locomotion, exploration, grooming, nesting), (c) submissive/defensive behaviors (flight, avoidance, tail up, upright, side defense, stretch attend, head flag, attempted escape from cage), and (d) aggressive behaviors (upright an side offense, chase and attack).

\subsection{Drug Infusion}

2.4.1 Experiments 1 and 2-Animals were removed from their home cage and gently restrained while the dummy stylet was removed. Muscimol (Sigma-Aldrich, $2.2 \mathrm{nmol}$ in 300 $\mathrm{nl}$ saline) or vehicle control (300 $\mathrm{nl}$ saline) was then unilaterally infused into the left or right $\mathrm{mPFC}$ over a 1.5 min period using a $1-\mu \mathrm{L}$ syringe (Hamilton, Reno, NV) connected to an mini-infusion pump (Harvard Apparatus, Holliston, MA) via polyethylene tubing. During the infusion procedure, the animal was free to move about in a small, clear polycarbonate cage. The injection needle (33-gauge) was kept in place for an additional 1 min before being 
removed to ensure complete diffusion of the drug after which the dummy stylet was replaced. Testing began 10 min after drug infusion.

We chose to use muscimol, a $\mathrm{GABA}_{\mathrm{A}}$ agonist, to inactivate the $\mathrm{mPFC} / \mathrm{BLA}$ for several reasons. First, $\mathrm{GABA}_{\mathrm{A}}$ receptors are widely distributed in the central nervous system, including the $\mathrm{mPFC}$, and infusion of muscimol into specific brain areas induces hyperpolarization (Martin and Ghez, 1999) and has been shown to reversibly suppress excitatory neurotransmission (Allen et al., 2008). In addition, the resulting suppression of neuronal activity is temporary, lasting up to several hours depending on dose (Majchrzak and DiScala, 2000). We based the dose of muscimol used in this study on our previous experiments showing that this dosage was the most effective in altering the acquisition and/ or expression of $\mathrm{CD}$ while at the same time not inducing unwanted behavioral side-effects (Markham and Huhman, 2008, Markham et al., 2010).

2.4.2 Experiment 3-Bicuculline methobromide (Sigma-Aldrich, $300 \mathrm{ng}$ in $300 \mathrm{nl}$ saline) or vehicle control ( $300 \mathrm{nl}$ saline) was unilaterally infused into the mPFC using the same procedure described above. The dose of bicuculline used in this experiment was based on pilot studies ensuring that this dose did not induce behavioral side effects as well as a previous study demonstrating that a similar dose was effective in blocking 8-OH-DPATinduced circadian phase shifts (Mintz, et al., 1997).

2.4.3 Experiment 4-Anisomycin (Sigma-Aldrich, $1.125 \mathrm{nmol}$ in $300 \mathrm{nl}$ saline) or vehicle control ( $300 \mathrm{nl}$ saline) was unilaterally infused into the mPFC using the same procedure described above, except that testing began 20 min after drug infusion. Anisomycin has been shown to impair memory by disrupting protein synthesis, and we have previously used this dose in the BLA to inhibit the acquisition of CD (Bourtchouladze et al. 1998; Markham and Huhman, 2008; Schafe and LeDoux, 2000).

2.4.4 Experiment 5-Bicuculline methobromide (Sigma-Aldrich, $200 \mathrm{ng}$ in $200 \mathrm{nl}$ saline) or vehicle control (200 nl saline) was bilaterally infused into the BLA using the same procedure described above. Testing began $10 \mathrm{~min}$ after infusion.

2.5.1 Site Verification-At the end of each experiment, hamsters were administered an overdose of Sleepaway euthanasia solution (Fort Dodge Animal Health, Fort Dodge, IA) and infused with $300 \mathrm{nl}$ of India ink to verify the placement of the injection needle. The brains were then removed and fixed in $10 \%$ buffered formalin for at least 48 hours before being sectioned on a Leica CM $3050 \mathrm{~S}$ cryostat. Thirty $\mu \mathrm{m}$ sections were taken and stained with cresyl violet and coverslipped with DPX. Sections were then examined under a lightmicroscope (Zeiss Axioplan 2) for placement verification. Only animals with injection sites within $0.3 \mathrm{~mm}$ of the target structure were included in the analysis.

2.5.2 Site Verification Results-Figure 1a shows the injection sites for all animals in Experiments 1-4 (mPFC) while Figure 1b shows the injection sites for animals in Experiment 5 (BLA). Only injections that were localized to within $0.3 \mathrm{~mm}$ of the target structure were included in the analysis. In addition, groups were collapsed over side of injection because there was no evidence of laterality (no significant difference between injections of the left and right $\mathrm{mPFC}$ ). In experiments in which several injection sites were deemed to be misses (i.e., greater than $0.3 \mathrm{~mm}$ from target structure), data from these subjects were analyzed separately as an anatomical miss control group.

2.6.1 Experiment 1 and 2: Effect of activation of $\mathrm{GABA}_{A}$ receptors in the mPFC on the acquisition or expression of CD-The goal of this experiment was to determine whether the temporary inactivation of the $\mathrm{mPFC}$ using the $\mathrm{GABA}_{\mathrm{A}}$ agonist 
muscimol would significantly enhance the acquisition (Experiment 1 ) and/or expression (Experiment 2) of CD. Animals (Experiment 1, $\mathrm{n}=32$; Experiment 2, $\mathrm{n}=30$ ) were randomly assigned to either the muscimol ( $2.2 \mathrm{nmol}$ in $300 \mathrm{nl}$ saline) or the vehicle ( $300 \mathrm{nl}$ saline) groups. For animals in Experiment 1, muscimol or vehicle was infused 10 min prior to being exposed to the RA for $15 \mathrm{~min}$. We did not use a sub-optimal defeat protocol in this experiment because we were unsure what effect muscimol infusions would have on CD. On the following day, animals were tested drug-free in their own home cage against a NAI for 5 min. In Experiment 2, animals were placed drug free into the home cage of a RA for $15 \mathrm{~min}$ defeat training. On the following day, they were infused with either muscimol or vehicle 10 min prior to be paired with a NAI in their own home cage.

In Experiment 1, injection needles were localized to within $0.3 \mathrm{~mm}$ of the $\mathrm{mPFC}$ in 25 of the 32 animals (Figure 1a). Other subjects $(n=5)$ had cannula placements that missed the target and were located in the intermediate region of the lateral septum (LSi). These animals were included in the anatomical miss control group. Additionally, the head caps on two of the subjects became detached during the infusion process. In Experiment 2, injection needles were localized to within $0.3 \mathrm{~mm}$ in 25 of 30 animals (Figure 1a). Other subjects ( $\mathrm{n}=5$ ) had cannula placements that missed the target and were located approximately $0.5 \mathrm{~mm}$ lateral $(n=1)$ or ventral to the $\mathrm{mPFC}(\mathrm{n}=4)$. These animals were included in the anatomical control group.

\subsubsection{Experiment 3: Inhibition of $\mathrm{GABA}_{A}$ receptors in the mPFC on the} acquisition of CD-The goal of Experiment 3 was to determine whether antagonism of $\mathrm{GABA}_{\mathrm{A}}$ receptors in the $\mathrm{mPFC}$ would impair the acquisition of CD. Animals $(\mathrm{n}=21)$ were randomly assigned to either the bicuculline ( $300 \mathrm{ng}$ in $300 \mathrm{nl}$ saline) or vehicle ( $300 \mathrm{nl}$ saline) groups and injected 10 min prior to being placed in the home cage of a RA for 15 min. On the following day, animals were tested drug-free in their own home cage against a NAI for $5 \mathrm{~min}$.

Injection needles were localized to within $0.3 \mathrm{~mm}$ of the $\mathrm{mPFC}$ in 19 of the 21 animals. One subject had a cannula placement that missed the target and was located approximately 0.5 $\mathrm{mm}$ caudal to the $\mathrm{mPFC}$. One animal had a clogged cannula during the injection procedure and was excluded from the analysis.

\subsubsection{Experiment 4: Inhibition of protein synthesis in the MPFC on the} acquisition of CD-The goal of Experiment 4 was to determine whether plasticity related to the defeat experience is mediated, at least in part, in the mPFC. Animals $(n=17)$ were randomly assigned to either the anisomycin ( $1.125 \mathrm{nmol}$ in $300 \mathrm{nl}$ saline) or vehicle ( $300 \mathrm{nl}$ saline) and injected $20 \mathrm{~min}$ prior to being placed into the home cage of a RA for $15 \mathrm{~min}$. On the following day, animals were tested drug-free in their own home cage against a NAI for 5 min. Injection needles were localized to within $0.3 \mathrm{~mm}$ of the $\mathrm{mPFC}$ in all 17 animals.

\subsubsection{Experiment 5: Inhibition of $\mathrm{GABA}_{A}$ receptors in the BLA on the} acquisition of $C D$ - The goal of Experiment 5 was to determine whether blockade of $\mathrm{GABA}_{\mathrm{A}}$ receptors in the BLA would potentiate the acquisition of CD. In Experiment 5, animals ( $\mathrm{n}=47$ ) were randomly assigned to either the bicuculline (100 or $200 \mathrm{ng}$ in $200 \mathrm{nl}$ saline) or vehicle ( $200 \mathrm{nl}$ saline) groups and injected $10 \mathrm{~min}$ prior to be being defeated by an RA for $5 \mathrm{~min}$. Based on our previous finding that muscimol infusion in the BLA impaired the acquisition of CD (Markham and Huhman, 2008), we hypothesized that bicuculline in the BLA would enhance CD. Therefore, in order to avoid a ceiling effect, we used a suboptimal defeat protocol for this experiment, which was comprised of a single 5-min pairing with the RA. 
Injection needles were localized bilaterally or unilaterally to within $0.3 \mathrm{~mm}$ of the BLA in 37 of the 47 animals (Figure 1b). Other subjects $(n=10)$ had cannula placements that missed the BLA bilaterally $(n=7)$, or had clogged cannula at the time of injection $(n=3)$. These animals were not included in the analysis. Of the remaining animals $(\mathrm{n}=37), 14 \mathrm{had}$ unilateral, while 23 had bilateral cannula placements aimed at the BLA.

\subsection{Statistical analysis}

The total duration (seconds) of each behavior displayed (Submissive/Defensive, Social, Nonsocial) was determined, and the mean total duration of each behavior was then compared using separate t-tests for independent samples (Experiments 1-4) and ANOVA (Experiment 5).

\section{Results}

\subsection{Histology}

Figure 2 is a photomicrograph of a representative coronal section of the mPFC (2a) and BLA (2b) showing the location of the injection needle and subsequent ink infusion. Table 1 summarizes the cannula placements, including hits and misses for all experiments in this study.

\subsection{Experiment 1: Inactivation of the MPFC enhanced the acquisition of CD}

As shown in Figure 3a, animals receiving muscimol displayed a significant increase in submissive and defensive behaviors $(\mathrm{t}(23)=-2.54, \mathrm{p}<0.05)$ and a significant reduction in non-social behaviors $(\mathrm{t}(23)=2.56, \mathrm{p}<0.05)$ compared to the vehicle control group. No significant differences were observed between the two groups in total duration of social behaviors. No instances of aggression were observed. In addition, animals in the anatomical miss control group that received muscimol $(n=4)$ exhibited levels of submission that were similar to the vehicle control group, indicating that the increased submission observed in the muscimol-mPFC group was site-specific.

\subsection{Experiment 2: Inactivation of the MPFC did not alter the expression of CD}

As shown in Figure 3b, inactivation of the MPFC prior to testing with a NAI did not significantly alter any of the behavioral measures, including submission and defensive behaviors. Analysis of the anatomical control group showed that in three of the four animals with infusion of muscimol in the LSi exhibited increased aggression, but no changes in submission (data not shown). This finding is consistent with a recent study in our lab showing that inactivation of the lateral septum (LS) with muscimol induces aggression in previously defeated hamsters (McDonald et al., in preparation).

\subsection{Experiment 3: Stimulation of the MPFC impaired the acquisition of CD}

As shown in Figure 4, infusion of bicuculline in the mPFC inhibited the acquisition of CD, as evidenced by a significant reduction in the duration of submissive and defensive behaviors during testing with a NAI $(t(17)=4.62, \mathrm{p}<0.001)$. In addition, there was a significant increase in social behavior in the muscimol group compared to the vehicle animals $(\mathrm{t}(17)=-3.85, \mathrm{p}<0.001)$.

\subsection{Experiment 4: Inhibition of protein synthesis in the MPFC did not impair the acquisition of CD}

As shown in Figure 5, infusion of anisomycin in the mPFC did not alter the acquisition of $\mathrm{CD}$, with no significant differences in total duration of submissive/defensive, social or nonsocial behavior between the two groups. 


\subsection{Experiment 5: Stimulation of the BLA did not enhance the acquisition of CD}

As shown in Figure 6, infusion of bicuculline did not affect the acquisition of CD, and no significant differences were observed between the bicuculline and vehicle groups on total duration of submissive, aggressive, social and non-social behaviors.

\section{Discussion}

In the present series of experiments, we demonstrate that the mPFC is a component of the neural circuit mediating the learned response to social defeat; temporary inactivation of the mPFC enhanced, while blockade of GABAergic receptors in the MPFC impaired the acquisition of $\mathrm{CD}$. We also found that while the MPFC is necessary for the acquisition of $\mathrm{CD}$, the plasticity related to the defeat experience does not appear to occur here. In addition, although we expected that disinhibition of the BLA might enhance CD following suboptimal defeat training, this was not the case because there was no significant difference in the duration of submissive behavior exhibited by the bicuculline-infused animals compared to the control group. This was perhaps surprising considering that we had previously demonstrated that inactivation, whether bilateral or unilateral, or inhibition of protein synthesis in the BLA was sufficient to disrupt the acquisition of CD (Markham and Huhman, 2008), and that overexpression of CREB in the BLA enhances the acquisition of CD (Jasnow et al., 2004). Thus, these results suggest that while the mPFC is both necessary and sufficient for $\mathrm{CD}$, simple blockade of GABAergic inhibition within the BLA is not sufficient to enhance $\mathrm{CD}$.

A large number of studies have suggested that the mPFC is involved in the modulation of emotional responses to aversive stimuli (however, see also Gewirtz, et al., 1997). For example, an early study by Holson (1986) showed that mPFC lesions increase fear reactivity to aversive stimuli (referred to as 'timidity'), while Morgan and LeDoux (1995) demonstrated that lesions of the mPFC enhance the acquisition of conditioned fear. Conversely, al Maskati and Zbrozyna (1989) found that electrical and chemical (D,Lhomocysteic acid) stimulation of the MPFC inhibits the increased cardiovascular tone elicited by electrical stimulation of the amygdala. A more recent study by Quirk and colleagues (2003) found that electrical stimulation of the mPFC reduces conditioned fear previously paired with an auditory CS. These bidirectional effects on fear reactivity following manipulation of the mPFC (stimulation vs. lesion) are consistent with our findings that pre-training inactivation of the mPFC using muscimol enhanced submissive/defensive behaviors, while disinhibition of this area via infusion of bicuculline impaired submission. Importantly, we believe that these effects are specific to the role of the $\mathrm{mPFC}$ on CD because an analysis of the defeat training sessions after muscimol/bicuculline infusions revealed no drug effects on either the amount of aggression exhibited by the RA or on the submissive behaviors exhibited by the subjects in response to attack, indicating that the drugs, themselves, did not directly alter the agonistic interactions. In terms of the role of the $\mathrm{mPFC}$ on expression to $\mathrm{CD}$, our finding that temporary inactivation of the mPFC did not affect the expression of $\mathrm{CD}$ was rather surprising. Indeed, evidence from a recent study (Sierra-Mercado et al., 2006) showing that inactivation of the mPFC blocks the expression of conditioned fear using a more traditional model led us to hypothesize that the mPFC would also be involved in the expression of CD. One possible explanation for this discrepancy is that while the Sierra-Mercado study (2006) used tetrodotoxin (TTX), a sodium channel blocker, as the inactivating agent, we used muscimol, a $\mathrm{GABA}_{\mathrm{A}}$ agonist. Therefore it is possible that TTX may have caused a more global inhibition of neural activity within the mPFC compared to muscimol, which might be more selective. Further studies will determine whether a more global inactivation of the $\mathrm{MPFC}$ using TTX or lidocaine might reveal an effect of the $\mathrm{mPFC}$ on the expression of CD. 
Previous work from our lab has demonstrated that plasticity related to the defeat experience occurs at least in part in the BLA (Markham and Huhman, 2008), and considering its extensive connectivity with the mPFC and the sufficiency of mPFC inactivation in enhancing $\mathrm{CD}$ acquisition demonstrated here, we hypothesized that the mPFC may also play a role in plasticity related to $\mathrm{CD}$. Several studies have demonstrated that inhibition of protein synthesis in the mPFC is effective in blocking extinction of fear memory (Santini et al., 2004), consolidation of remote memory (Blum et al., 2006) and inhibitory avoidance (Zhang et al., 2011). The results of Experiment 4, however, indicated that infusion of anisomycin did not impair the acquisition of CD. There are several possible explanations for this discrepancy. One possibility concerns the use of the conditioned defeat model, itself, as compared with more traditional fear conditioning models. Both the Zhang and Santini studies used models that are based on a single sensory modality to form a simple US-CS association. On the other hand, CD is a more complex model that most likely involves multiple sensory modalities and therefore necessarily engages multiple neural pathways. Simply inactivating protein synthesis in one structure in this circuit that has been shown to project extensively to the BLA (an area that we have shown to be involved in plasticity for $\mathrm{CD}$ ) may not have been sufficient to impair plastic changes related to social defeat stress. Additionally, we must also acknowledge the possibility that the mPFC is indeed a critical site for plasticity underlying $\mathrm{CD}$, but that plasticity for defeat-induced memory is not dependent on protein synthesis in this brain area.

In Experiment 5, bicuculline infusions in the BLA failed to enhance the acquisition of CD. This was an unexpected finding, considering previous data from our lab has shown that temporary inactivation of the BLA via infusion of muscimol is effective in impairing the acquisition of CD (Jasnow and Huhman, 2001; Markham and Huhman, 2008), and overexpression of CREB in the BLA enhances acquisition of CD (Jasnow, et al., 2004). We had therefore hypothesized that stimulation of this area via infusion of bicuculline would enhance CD. However, the present data indicate that simple disinhibition of BLA neurons via blocking GABAergic receptors is not sufficient to enhance $\mathrm{CD}$. This finding is inconsistent with reports that infusion of bicuculline in the amygdala is sufficient to enhance the memory formation in some models of conditioned fear (Brioni, et al., 1989). Other than simple differences in fear conditioning models used, one explanation for this inconsistency is that the neural and molecular mechanisms underlying $\mathrm{CD}$ are mediated by another neurotransmitter system, such as glutamate, and the simple lack of inhibitory tone in the BLA does not directly lead to stimulation of the critical excitatory output for CD. It is possible that direct stimulation of the excitatory projection neurons in the BLA, instead of disinhibiting GABAergic mechanisms, may be more effective in enhancing memory formation related to $\mathrm{CD}$. This would be consistent with our previous finding that overexpression of CREB in the BLA significantly enhanced the acquisition of CD following a sub-optimal defeat (Jasnow et al., 2005). This is especially significant considering CREB phosphorylation and resulting gene expression is, at least in part, dependent on glutamateinitiated activation of NMDA receptors (Rajadhyaksha et al., 1999). In line with these arguments, we have also demonstrated that infusion of the NMDA receptor antagonist DL-2-amino-5-phosphonopentanoic acid (AP5) blocked the acquisition and expression of CD (Jasnow et al., 2004). Additionally, several other studies support the idea that glutamate may be responsible for mediating memory formation related to conditioned fear. For example, infusion of either the metabotropic glutamate receptor antagonist 2-methyl-6(phenylethynyl)-pyridine (MPEP) or the AMPA/kainate receptor antagonist NBQX blocked the acquisition of fear learning (Schulz et al., 2001; Walker et al., 2005). It is also possible that site specific differences within the amygdala may explain these findings. For example, disinhibition of the central nucleus (CeA), which is the primary output pathway of the amygdala, may be more effective in enhancing the acquisition of CD. Future studies will 
examine this possibility by infusing bicuculline in the CeA in order to determine whether this will result in an enhancement of CD.

While the present data showing that pharmacological manipulation of the mPFC affected the acquisition of $\mathrm{CD}$ is consistent with a number of other studies, it should be noted that there are also some contradictory data. For example, while some studies (Holson, 1986; Morgan and LeDoux, 1995; Sacchetti et al., 2002; Vouimba et al., 2000) have demonstrated that lesions and/or inactivation of the mPFC enhance conditioned fear, others have either found no effect (Sierra-Mercado et al., 2006) or that lesions actually impair fear memory (Frysztak and Neafsey, 1991). These differences may be attributed by any number of factors, including the use of a variety of fear conditioning models, different methods used to inactivate the region of interest (i.e., permanent vs. temporary inactivation) as well as sitespecific differences within the mPFC, itself. Indeed, recent evidence is beginning to suggest that the dorsomedial prefrontal cortex (dmPFC) mediates fear acquisition (Holson, 1986; Morgan and LeDoux, 1995; Sacchetti et al., 2002), while the ventromedial prefrontal cortex (vmPFC) mediates expression and/or extinction of conditioned fear (Blum et al., 2006; Sierra-Mercado et al., 2006). Because of the ambiguity of the existing data, as well as the fact that the neural circuit mediating $\mathrm{CD}$ is not as well-characterized compared to more conventional models of conditioned fear, we purposefully infused a somewhat larger volume of the pharmacological compounds (muscimol, bicuculline, or anisomycin) in order to potentially affect the major portions of the mPFC, including the dmPFC and vmPFC. It must be stated that smaller volume injections aimed specifically at mPFC subdivisions might clarify this point and should be pursued as a future direction for this work.

There is growing evidence that there is a functional interaction between the mPFC and amygdala in mediating certain aspects of conditioned fear. Indeed, our own studies have now demonstrated that temporary inactivation of the mPFC and BLA have opposing effect on the acquisition of $\mathrm{CD}$. This would seem to support the idea that the mPFC functions to inhibit the activity of the amygdala. Akirav and Maroun (2007) have recently suggested such a role for the mPFC and amygdala such that under normal conditions the mPFC is active and exerts an inhibitory tone on amygdalar output. In contrast, during times of stress the inhibitory tone of the mPFC on the amygdala is significantly reduced, thereby activating or enhancing the output pathways of the amygdala and leading to increased fear behaviors. In the context of the present experiment, this hypothesis is consistent, because we show that stimulation impaired, while inactivation of the mPFC, enhanced the acquisition of CD. Importantly, these effects were obtained by activating or inhibiting mPFC activity during social defeat stress. In contrast, previous studies reporting similar results have used traditional fear conditioning models that utilize simple CSs, such as lights or tones that depend on a single sensory modality. We believe the present results extend these findings by showing that learning in a more complex behavioral system, such as that which occurs during social defeat stress, is also modulated by the inhibitory interaction between the mPFC and amygdala. The exact mechanism by which this inhibition occurs is still under debate, especially considering that the $\mathrm{mPFC}$ projections to the amygdala are excitatory (Smith et al., 2000). However, Quirk and colleagues (2003) have suggested that the inhibition of the amygdala via $\mathrm{mPFC}$ projections involve inhibitory interneurons that gate transmission of BLA output pathways to the CeA. In support of this hypothesis, they demonstrate that electrical stimulation of the $\mathrm{mPFC}$ reduces the responsiveness of neurons in the $\mathrm{CeA}$, and as mentioned above, it is possible that enhancement of CD may have been observed had we examined the CeA. Future studies will directly examine this possibility as well as explore further possible functional connectivity between the mPFC and amygdala. 


\section{Acknowledgments}

The authors would like to thank Alisa Norvelle, M.S., for her overall technical assistance and Anwar Lopez for assistance with the photomicrographs. This research was supported by the National Institutes of Health RO1 MH62044 to KLH. All procedures were approved by the Georgia State University Animal Care and Use Committee and comply with US law.

\section{References}

Akirav I, Maroun M. The role of the medial prefrontal cortex-amygdala circuit in stress effects on the extinction of fear. Neural. Plast. 2007; 2007:30873. [PubMed: 17502909]

Allen TA, Narayanan NS, Kholodar-Smith DB, Zhao Y, Laubach M, Brown TH. Imaging the spread of reversible brain inactivations using fluorescent muscimol. J. Neurosci. Methods. 2008; 171:30 38. [PubMed: 18377997]

al Maskati HA, Zbrozyna AW. Stimulation in prefrontal cortex area inhibits cardiovascular and motor components of the defence reaction in rats. J. Auton. Nerv. Syst. 1989; 28:117-125. [PubMed: 2625500]

Blum S, Hebert AE, Dash PK. A role for the prefrontal cortex in recall of recent and remote memories. Neuroreport. 2006; 17:341-344. [PubMed: 16462609]

Bourtchouladze R, Abel T, Berman N, Gordon R, Lapidus K, Kandel ER. Different training procedures recruit either one or two critical periods for contextual memory consolidation, each of which requires protein synthesis and PKA. Learn. Mem. 1998; 5:365-374. [PubMed: 10454361]

Brioni JD, Nagahara AH, McGaugh JL. Involvement of the amygdala GABAergic system in the modulation of memory storage. Brain Res. 1989; 487:105-112. [PubMed: 2752279]

Davis M. Neurobiology of fear responses: the role of the amygdala. J. Neuropsychiatry Clin. Neurosci. 1997; 9:382-402. [PubMed: 9276841]

Davis, M. The role of the amygdala in conditioned and unconditioned fear and anxiety. In: Aggleton, JP., editor. The amygdala. Oxford University Press; New York: 2000. p. 213-288.

Day DE, Cooper MA, Markham CM, Huhman KL. NR2B subunit of the NMDA receptor in the basolateral amygdala is necessary for the acquisition of conditioned defeat in Syrian hamsters. Behav. Brain. Res. 2011; 217:55-59. [PubMed: 20933543]

Floyd NS, Price JL, Ferry AT, Keay KA, Bandler R. Orbitomedial prefrontal cortical projections to distinct longitudinal columns of the periaqueductal gray in the rat. J. Comp. Neurol. 2000; 422:556-578. [PubMed: 10861526]

Floyd NS, Price JL, Ferry AT, Keay KA, Bandler R. Orbitomedial prefrontal cortical projections to hypothalamus in the rat. J. Comp. Neurol. 2001; 432:307-328. [PubMed: 11246210]

Frysztak RJ, Neafsey EJ. The effect of medial frontal cortex lesions on respiration, "freezing", and ultrasonic vocalization during conditioned emotional responses in rats. Cereb. Cortex. 1991; 1:418-425. [PubMed: 1822749]

Gewirtz JC, Falls WA, Davis M. Normal conditioning inhibition and extinction of freezing and fearpotentiated startle following electrolytic lesions of medial prefrontal cortex in rats. Behav. Neurosci. 1997; 111:712-726. [PubMed: 9267649]

Holson R,R. Mesial prefrontal cortical lesions and timidity in rats 1. Reactivity to aversive stimuli. Physiol. Behav. 1986; 37:221-230. [PubMed: 3737731]

Huhman KL, Solomon MB, Janicki M, Harmon AC, Lin SM, Israel JE, Jasnow AM. Conditioned defeat in male and female Syrian hamsters. Horm. Behav. 2003; 44:293-299. [PubMed: 14609551]

Jasnow AM, Huhman KL. Activation of $\mathrm{GABA}_{\mathrm{A}}$ receptors in the amygdala blocks the acquisition and expression of conditioned defeat in Syrian hamsters. Brain. Res. 2001; 920:142-150. [PubMed: 11716820]

Jasnow AM, Shi C, Israel JE, Davis M, Huhman KL. Memory of social defeat is facilitated by cAMP response element-binding protein overexpression in the amygdala. Behav. Neurosci. 2005; 119:1125-1130. [PubMed: 16187840]

LeDoux JE. Emotion circuits in the brain. Ann. Rev. Neurosci. 2000; 23:155-184. [PubMed: 10845062] 
Majchrzak M, Di Scala G. GABAA and muscimol as reversible inactivation tools in learning and memory. Neural. Plast. 2000; 7:19-29. [PubMed: 10709211]

Maren S. Neurobiology of Pavlovian fear conditioning. Annu. Rev. Neurosci. 2001; 24:897-931. [PubMed: 11520922]

Markham CM, Huhman KL. Is the medial amygdala part of the neural circuit modulating conditioned defeat in Syrian hamsters? Learn. Mem. 2008; 15:6-12. [PubMed: 18174368]

Markham CM, Taylor SL, Huhman KL. Role of amygdala and hippocampus in the neural circuit subserving conditioned defeat in Syrian hamsters. Learn. Mem. 2010; 17:109-116. [PubMed: 20154357]

Martin JH, Ghez C. Pharmacological inactivation in the analysis of the central control of movement. J. Neurosci. Methods. 1999; 86:145-159. [PubMed: 10065983]

McDonald AJ, Mascagni F, Guo L. Projections of the medial and lateral prefrontal cortices to the amygdala: a Phaseolus vulgaris leucoagglutinin study in the rat. Neuroscience. 1996; 71:55-75. [PubMed: 8834392]

Milad MR, Quirk GJ. Neurons in the medial prefrontal cortex signal memory for fear extinction. Nature. 2002; 420:70-74. [PubMed: 12422216]

Milad MR, Vidal-Gonzalez I, Quirk GJ. Electrical stimulation of medial prefrontal cortex reduces conditioned fear in a temporally specific manner. Behav. Neurosci. 2004; 118:389-394. [PubMed: 15113265]

Mintz EM, Gillespie CF, Marvel CL, Huhman KL, Albers HE. Serotonergic regulation of circadian rhythms in Syrian hamsters. Neuroscience. 1997; 79:563-569. [PubMed: 9200739]

Morgan MA, Romanski LM, LeDoux JE. Extinction of emotional learning: contribution of medial prefrontal cortex. Neurosci. Lett. 1993; 163:109-113. [PubMed: 8295722]

Morgan MA, LeDoux JE. Differential contribution of dorsal and ventral medial prefrontal cortex to the acquisition and extinction of conditioned fear in rats. Behav. Neurosci. 1995; 109:681-688. [PubMed: 7576212]

Morin, LP.; Wood, RI. A stereotaxic atlas of the Golden hamster brain. Academic Press; San Diego, CA: 2001

Potegal M, Huhman K, Moore T, Meyerhoff J. Conditioned defeat in the Syrian golden hamster (Mesocricetus auratus). Behav. Neural. Biol. 1993; 60:93-102. [PubMed: 8117243]

Quirk GJ, Likhtik E, Pelletier JG, Paré D. Stimulation of medial prefrontal cortex decreases responsiveness of central amygdala output neurons. J. Neurosci. 2003; 23:8800-8807. [PubMed: 14507980]

Rajadhyaksha A, Barczak A, Macias W, Leveque JC, Lewis SE, Konradi C. L-Type Ca(2+) channels are essential for glutamate-mediated CREB phosphorylation and c-fos gene expression in striatal neurons. J. Neurosci. 2001; 19:6348-6359. [PubMed: 10414964]

Sacchetti B, Baldi E, Lorenzini CA, Bucherelli C. Differential contribution of some cortical sites to the formation of memory traces supporting fear conditioning. Exp. Brain Res. 2002; 146:223-232. [PubMed: 12195524]

Santini E, Ge H, Ren K, Peña de Ortiz S, Quirk GJ. Consolidation of fear extinction requires protein synthesis in the medial prefrontal cortex. J. Neurosci. 2004; 24:5704-5710. [PubMed: 15215292]

Schafe GE, LeDoux JE. Memory consolidation of auditory pavlovian fear conditioning requires protein synthesis and protein kinase A in the amygdala. J. Neurosci. 2000; 20:RC96. [PubMed: 10974093]

Schulz B, Fendt M, Gasparini F, Lingenhöhl K, Kuhn R, Koch M. The metabotropic glutamate receptor antagonist 2-methyl-6-(phenylethynyl)-pyridine (MPEP) blocks fear conditioning in rats. Neuropharmacology. 2001; 41:1-7. [PubMed: 11445180]

Sierra-Mercado D Jr, Cocoran KA, Lebrón-Milad K, Quirk GJ. Inactivation of the ventromedial prefrontal cortex reduces expression of conditioned fear and impairs subsequent recall of extinction. Eur. J. Neurosci. 2006; 24:1751-1758. [PubMed: 17004939]

Smith Y, Paré JF, Paré D. Differential innervation of parvalbumin-immunoreactive interneurons of the basolateral amygdaloid complex by cortical and intrinsic inputs. J. Comp. Neurol. 2000; 416:496508. [PubMed: 10660880] 
Vouimba RM, Garcia R, Baudry M, Thompson RF. Potentiation of conditioned freezing following dorsomedial prefrontal cortex lesions does not interfere with fear reduction in mice. Behav. Neurosci. 2000; 114:720-724. [PubMed: 10959531]

Walker DL, Davis M. The role of amygdala glutamate receptors in fear learning, fear-potentiated startle, and extinction. Pharmacol. Biochem. Behav. 2002; 71:379-392. [PubMed: 11830172]

Walker DL, Paschall GY, Davis M. Glutamate receptor antagonist infusions into the basolateral and medial amygdala reveal differential contributions to olfactory vs. context fear conditioning and expression. Learn. Mem. 2005; 12:120-129. [PubMed: 15774945]

Zhang Y, Fukushima H, Kida S. Induction and requirement of gene expression in the anterior cingulated cortex and medial prefrontal cortex for the consolidation of inhibitory avoidance memory. Mol. Brain. 2011; 4:1-11. [PubMed: 21211057] 
Highlights: The medial prefrontal cortex is both necessary and sufficient for the acquisition of conditioned defeat in Syrian hamsters

Infusion of muscimol into the mPFC enhanced acquisition of conditioned defeat

Infusion of bicuculline into the mPFC impaired acquisition of conditioned defeat

Infusion of anisomycin did not affect acquisition of conditioned defeat

The mPFC is an integral component mediating the effects of social defeat stress

However, plasticity to the defeat experience occurs elsewhere 


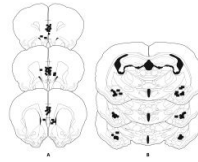

Figure 1a and $1 b$.

Histological reconstructions of injection sites for animals receiving infusions of muscimol/ bicuculline/anisomycin into the mPFC in Experiments 1-4 (a) or bicuculline into the BLA in Experiment 5 (b). Black dots represent the site of injection into the mPFC or BLA, while rectangles represent misplaced injection sites. Dots and rectangles may represent more than one placement. Drawings are adapted from Morin and Wood (2001). 


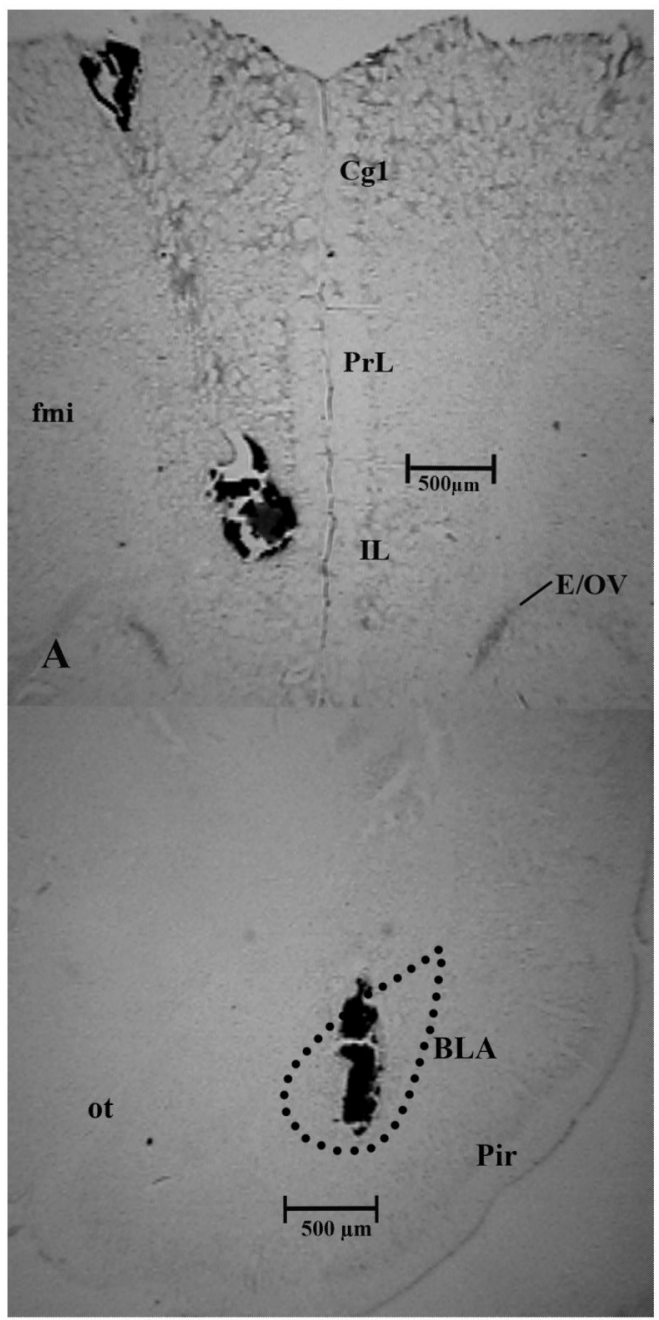

Figure 2a and $2 b$.

Representative photomicrograph is shown of a coronal brain section of the MPFC (2a) and BLA (2b). The needle tract and ink injection are clearly visible and indicate an injection site approximately $3.2 \mathrm{~mm}$ (mPFC) and $0.2 \mathrm{~mm}$ (BLA) rostral to bregma. Injection volume of the ink was identical to the drug/vehicle volume used in the experiments. Abbreviations: mPFC - medial prefrontal cortex, Cg1 - cingulate cortex, area 1, PrL - prelimbic cortex, IL - infralimbic cortex, E/OV - ependymal layer/olfactory ventricle, fmi - forceps minor corpus callosum, BLA - basolateral amygdala, Pir - piriform cortex, ot - optic tract. 

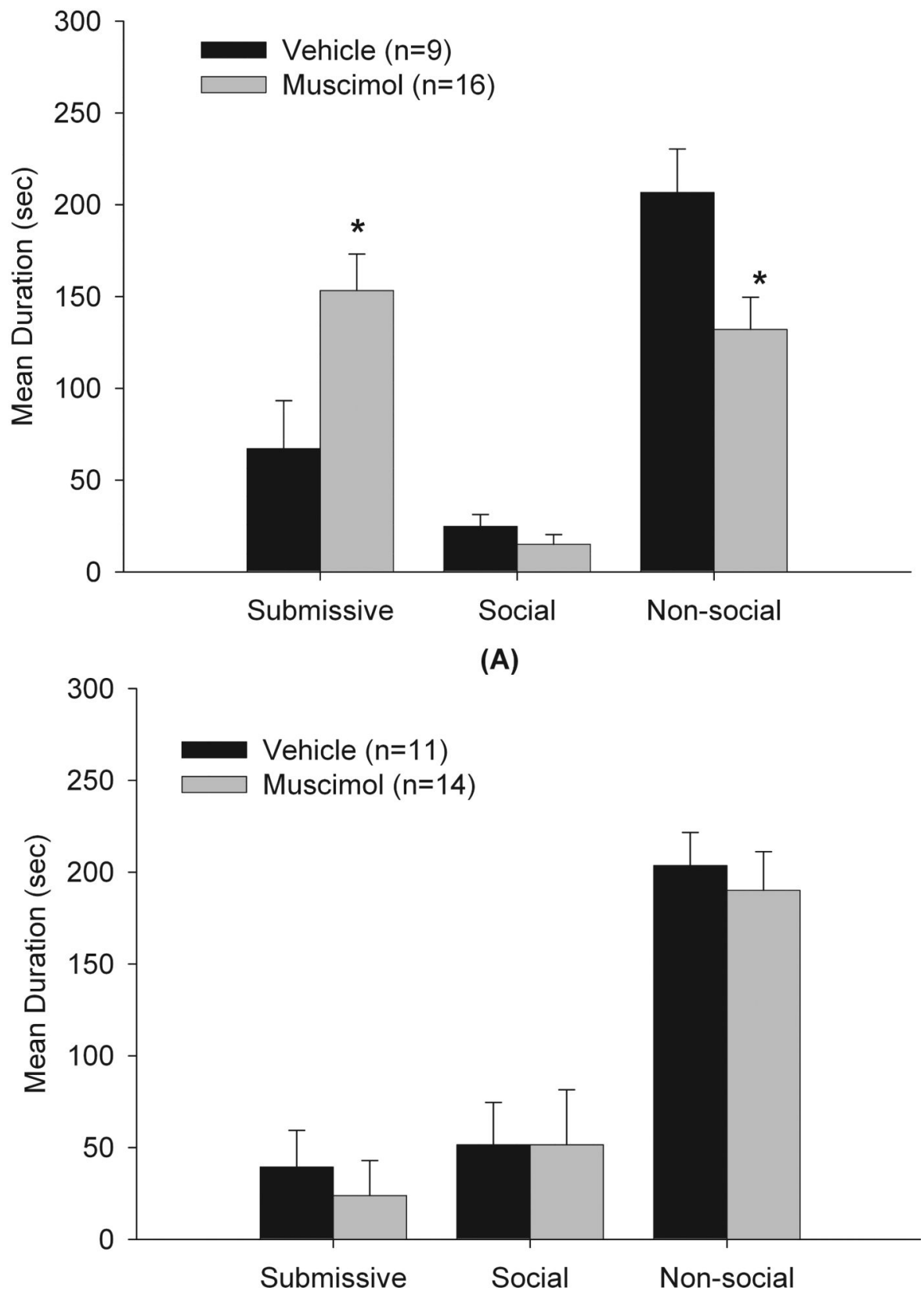

(B)

Figure 3a and $\mathbf{3 b}$.

Total duration (mean \pm S.E.M.) of behaviors exhibited during the 5-min test with a nonaggressive intruder (NAI). Animals received infusions of muscimol or saline into the mPFC $10 \mathrm{~min}$ prior to being defeated for $15 \mathrm{~min}(2 \mathrm{a})$ or prior to testing with a NAI (2b). * indicates significant differences at $(\mathrm{p}<.05)$. 


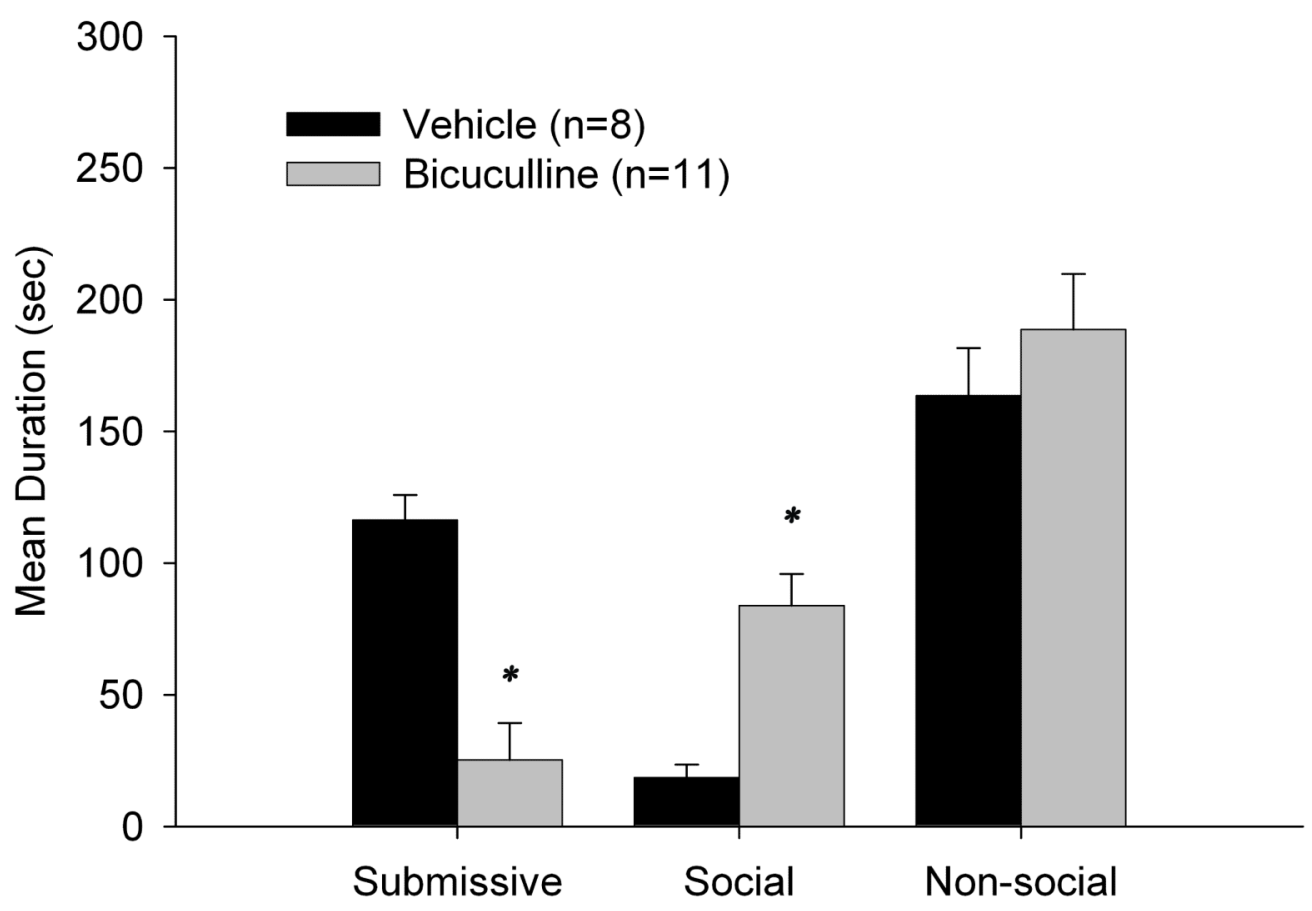

Figure 4.

Total duration (mean \pm S.E.M.) of behaviors exhibited during the 5-min test with a NAI. Animals received infusions of bicuculline or saline into the mPFC $10 \mathrm{~min}$ prior to being defeated for 15 min. * indicates significant differences at $(\mathrm{p}<.001)$. 


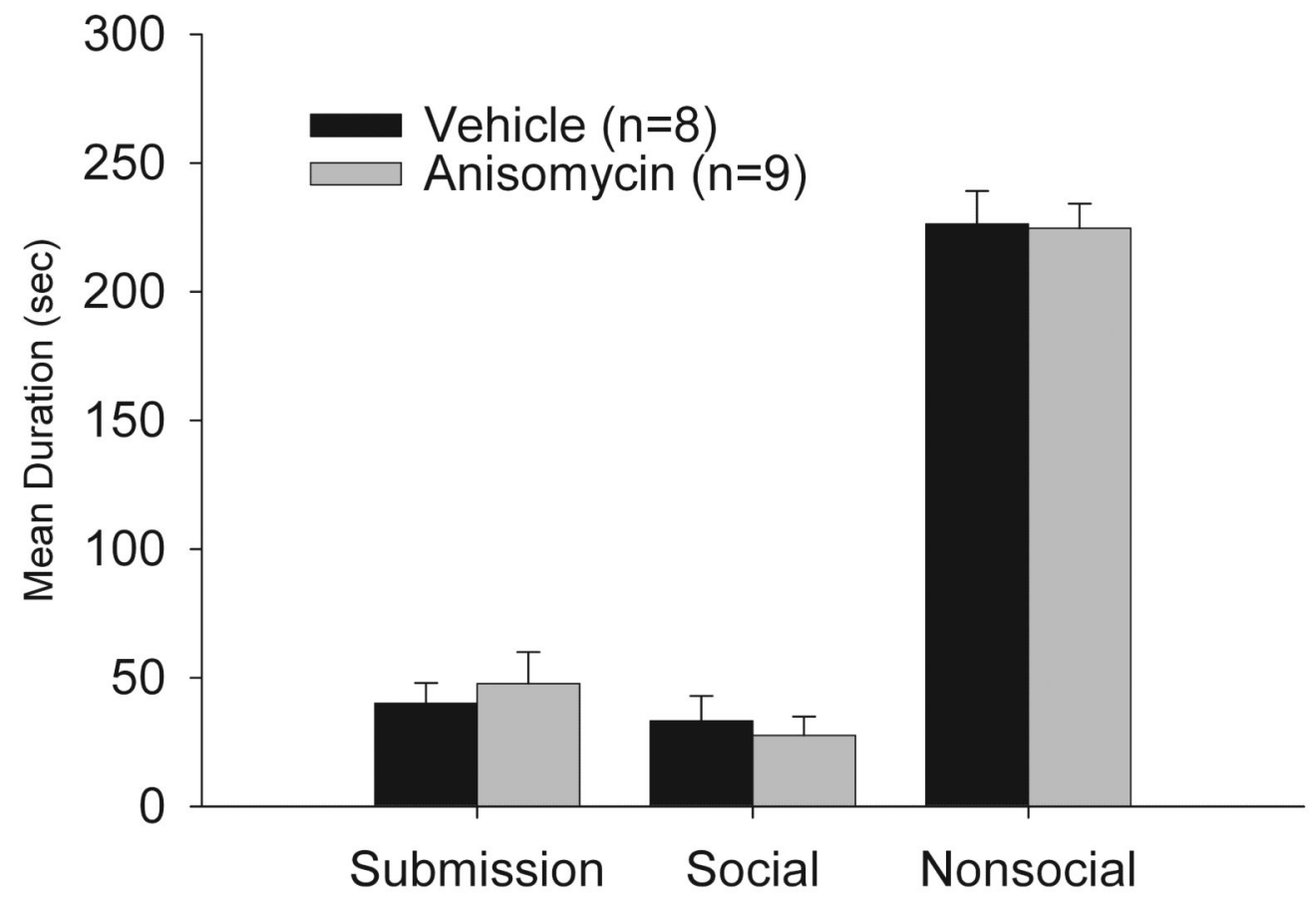

Figure 5.

Total duration (mean \pm S.E.M.) of behaviors exhibited during the 5-min test with a NAI. Animals received infusions of anisomycin or saline into the $\mathrm{mPFC} 20 \mathrm{~min}$ prior to being defeated for $15 \mathrm{~min}$. 


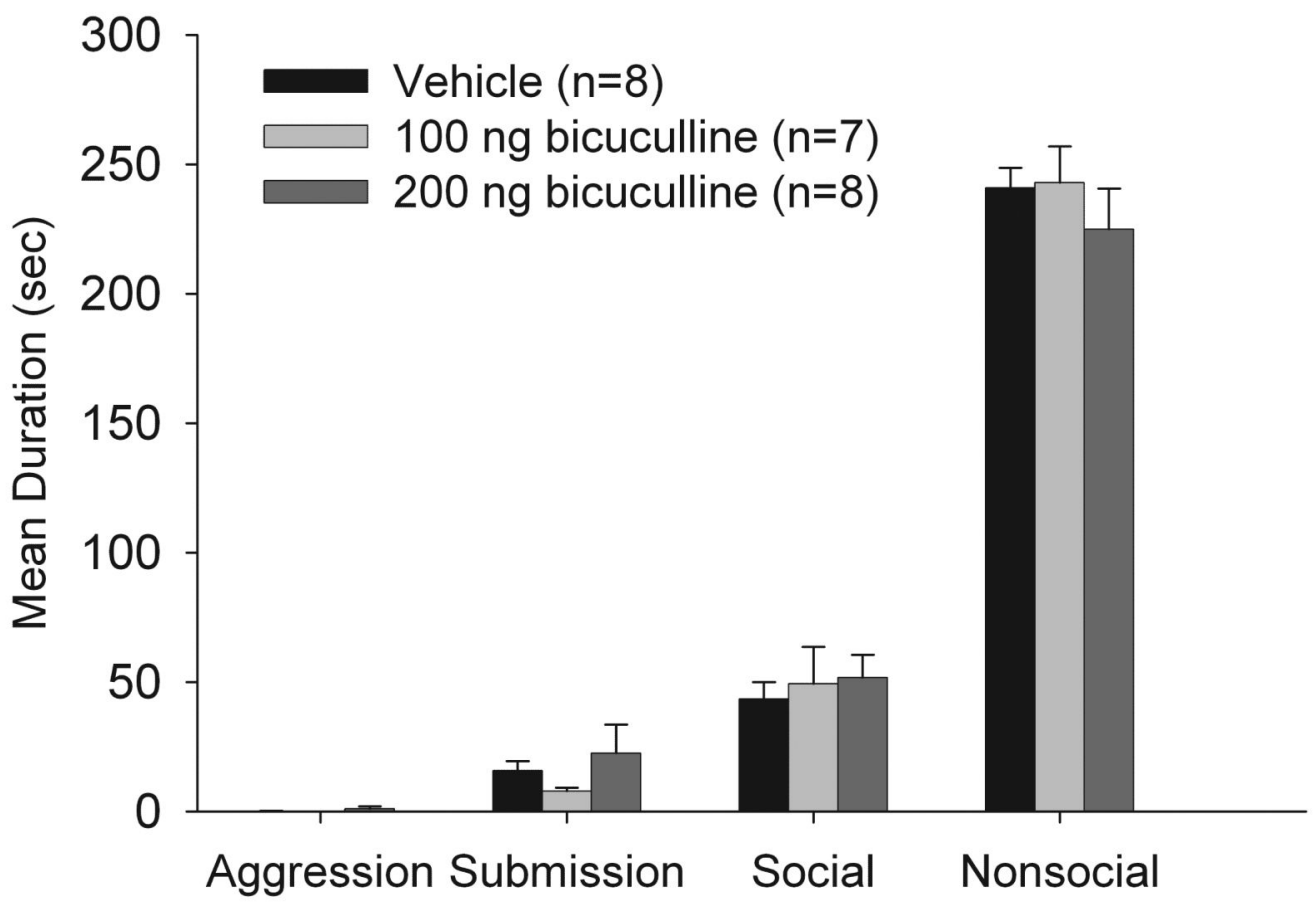

Figure 6.

Total duration (mean \pm S.E.M.) of behaviors exhibited during the 5-min test with a NAI. Animals received infusions of bicuculline or saline into the BLA 10 min prior to being defeated for $5 \mathrm{~min}$. 


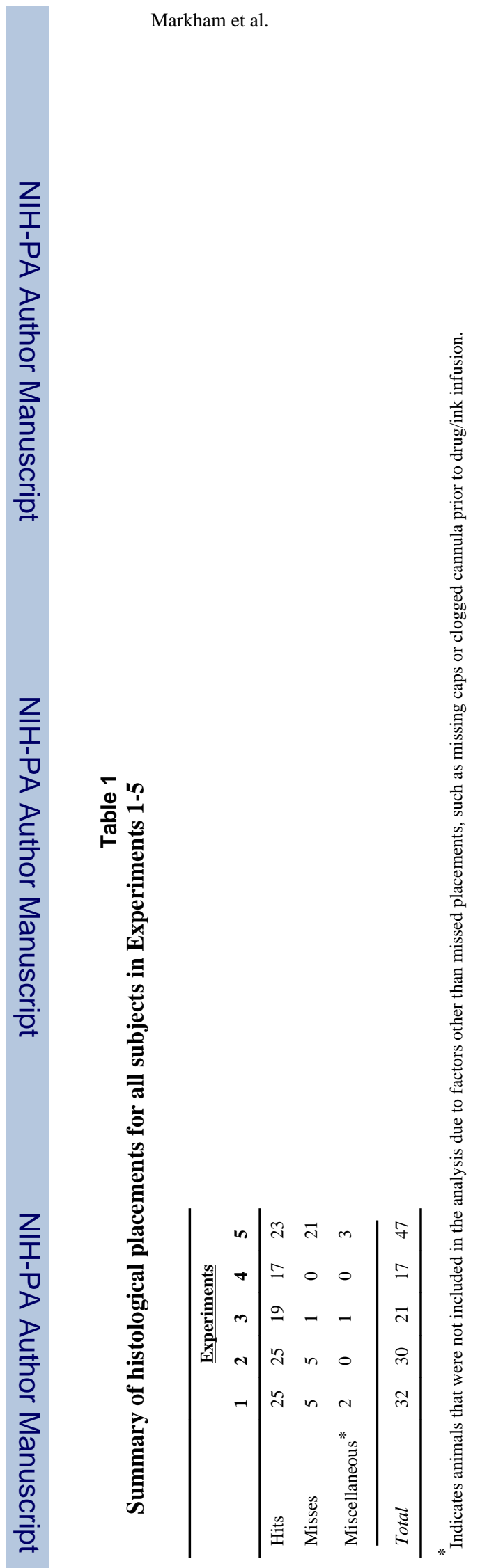

Neuropharmacology. Author manuscript; available in PMC 2013 February 1. 